\title{
ANAESTHESIA FOR INTRACRANIAL ANEURYSMS WITH HYPOTENSION AND SPONTANEOUS RESPIRATION
}

\author{
G.R. SELLeRY, M.D., F.R.C.P.(c), R.R. AitKeN, M.D., G.R.C.P.(c), AND \\ C.G. Drake, M.D., F.R.C.S. (c) *
}

A MAJOR PROBLEM affecting the surgical treatment of intracranial aneurysms is the rupture of the aneurysm prior to clipping. To prevent this occurrence the pressure within the aneurysm must be kept low. This was done in the past either by compressing the vessels supplying the aneurysm, in which case hypothermia was required, or by controlled hypotension. Until 1962 in the Neurosurgical Unit of the Victoria Hospital in London, Ontario, operation was done early after the bleeding and mainly under moderate hypothermia with controlled ventilation. Many anaesthetic agents were used and controlled hypotension was added in some cases. Although the surgical conditions were generally adequate, postoperative arterial spasm was a major factor in the prognosis. ${ }^{1}$ The anaesthetic management and the time interval between the haemorrhage and operation seemed to affect the incidence of postoperative $\operatorname{spasm}^{2}$ ( Table I).

When the operation was done early, the use of hypothermia seemed to predispose to postoperative arterial spasm, particularly when it was associated with artificial ventilation (Table II). As a consequence of this study, early operation was abandoned except when a significant clot was present or when there was repeated bleeding, and an attempt was made to utilize an anaesthetic technique that would give the surgeon optimal conditions without using hypothermia and controlled ventilation.

A fairly standard anaesthetic technique is used by three anaesthetists involved in these cases which are operated upon usually six or more days after a haemorrhage. This technique includes light halothane anaesthesia with spontaneous ventilation throughout and controlled hypotension.

Spontaneous respiration was felt to be advantageous because mild hypercarbia was produced which, when added to the effect of halothane, tended to increase cerebral blood flow. Although this would tend to raise intracranial pressure prior to craniotomy and to increase brain size when the dura was open, so making surgery difficult; it could be compensated for by drainage of cerebro-spinal fluid (CSF). After the dura was opened, CSF was removed through a catheter placed in the subarachnoid space at the level of L3-4 or L4-5. ${ }^{3}$ No problems arose, provided that drainage was stopped if the blood pressure rose or the heart rate decreased. Mannitol was sometimes used as well, although improper timing of its use may lead to hypervolaemia and later difficulty with the management of the hypotension. The level of hypotension aimed for was about $40 \mathrm{~mm} \mathrm{Hg}$ mean.

\footnotetext{
*From the Department of Anaesthesia and the Department of Neurosurgery, University of Western Ontario, and Victoria Hospital, London, Ontario.
} 
TABLE I

Number of Cases ANalysed at Victoria Hospital, London, Prior to 1962 with Post-operative Arteriai.

SPasm and its Relation to Time Interval From BleEd to SuRgery

\begin{tabular}{lr}
\hline Cases analysed & 175 \\
Cases having postoperative angiography & 83 \\
Arterial spasm & 35 \\
No arterial spasm & 48 \\
Time interval bleed to surgery & 5.1 days \\
With spasm & 10.7 days \\
No spasm &
\end{tabular}

TABLE II

Effects on Arterial Spasm Prior to 1962 of Three VARLABLES: HyPOTHERMIA, HYPOTENSION AND TYPE OF VENTILATION

\begin{tabular}{lc}
\hline \hline & Spasm \\
\hline Effect of hypothermia with ippv & $86 \%$ \\
Effect of hypothermia with spontaneous ventilation & $39 \%$ \\
Effect of hypotension alone & $25 \%$ \\
Effect of hypothermia and hypotension & $51 \%$ \\
\hline
\end{tabular}

The mild hypercarbia achieved with spontaneous ventilation avoided respiratory alkalosis, which would shift the oxygen dissociation curve to the left, decrease the cerebral blood flow and possibly have a harmful effect on cerebral oxygenation. ${ }^{4}$ The use of hypothermia would certainly increase this potentially harmful effect by also shifting the oxygen dissociation curve to the left.

Probably the most valuable aspect of spontaneous ventilation is its use as a monitor. It was found that during hypotension changes in the character of respiration signalled inadequate perfusion of the vital centres. ${ }^{5}$ The respiratory rate changes very little but the tidal volume decreases. It is not common to see the slow deep irregular respirations of air hunger, although this too might be taken as a sign of inadequate perfusion. This monitoring was very valuable in the treatment of some basilar artery aneurysms in preventing irreversible damage due to retractor ischaemia. It should be emphasized that retractor ischaemia of the frontal lobes during operation on the anterior communicating aneurysm will not affect the respiratory centre. Therefore the respiratory signs are useful only in relation to perfusion of the vital centres. Almost without exception changes in respiration preceded cardiac arrythmias in the normothermic patient.

Blood gases were measured on numerous occasions throughout operation so that an indwelling arterial catheter was used in virtually all cases. The inspired oxygen concentrations were usually adjusted to 50 per cent during hypotension to prevent hypoxaemia. As in all long operations the $\mathrm{PaO}$.2 was lower than expected due to many factors associated with anaesthesia. ${ }^{6}$ The $\mathrm{PaO}_{2}$ was rarely below $100 \mathrm{~mm} \mathrm{Hg}$ although $\mathrm{F}_{\mathrm{I}} \mathrm{O}_{2}$ was usually quite high. At normal levels of blood pressure $\mathrm{PCO}_{2}$ was usually maintained between 40 and $50 \mathrm{~mm} \mathrm{Hg}$. A small number of patients developed very high $\mathrm{PaCO}_{2}$ during hypotension. This was presumably due to high physiological dead space resulting from hypoperfusion 
TABLE III

Survey of 15 Patients' Blood Gases after Hypotension of Various Durations (Mean Brood Pressure 40-45 MM Hg)

\begin{tabular}{lrrrrrr}
\hline \hline Patient & $\begin{array}{c}\text { Time } \\
\text { (min) }\end{array}$ & $\mathrm{PO}_{2}$ & $\mathrm{pH}$ & $\mathrm{PCO}_{2}$ & $\mathrm{HCO}_{3}$ & $\mathrm{BE}$ \\
\hline (1) $10684 / 71$ & 20 & 153 & 7.34 & 41 & 22 & -3 \\
& 55 & 168 & 7.36 & 39 & 22 & -3 \\
(2) $22389 / 71$ & 5 & 69 & 7.26 & 39 & 17 & -9 \\
(3) $7250 / 71$ & 45 & 185 & 7.29 & 44 & 20 & -5 \\
(4) $21991 / 71$ & 20 & 99 & 7.365 & 30 & 18 & -7 \\
(5) $19848 / 71$ & 25 & 232 & 7.24 & 58 & 21 & -4 \\
(6) $18810 / 71$ & 45 & 164 & 7.36 & 38 & 21 & -4 \\
(7) $23490 / 71$ & 20 & 179 & 7.375 & 35 & 21 & -4 \\
(8) $24255 / 71$ & 25 & 161 & 7.39 & 39 & 23 & -1 \\
(9) $27702 / 71$ & 20 & 133 & 7.33 & 52 & 25 & +1 \\
(10) $26844 / 71$ & 30 & 135 & 7.36 & 40 & 22 & -3 \\
(11) $25965 / 71$ & 70 & 157 & 7.14 & 73 & 19 & -6 \\
(12) $25582 / 71$ & 35 & 212 & 7.43 & 39 & 26 & +1 \\
(13) $26 / 72$ & 25 & 92 & 7.32 & 60 & 26 & +3 \\
(15) $2339 / 72$ & 5 & 110 & 7.31 & 50 & 23 & -2 \\
\hline
\end{tabular}

of lungs and under-ventilation during hypotension. ${ }^{7}$ Occasionally when hypotension was excessive and the $\mathrm{PaCO}_{2}$ rose too high, respiration had to be assisted for short intervals.

A survey of blood gases sampled during hypotension in a recent series of 15 patients illustrates this point (Table III). Four of the patients had a $\mathrm{PCO}_{2}$ above $50 \mathrm{~mm} \mathrm{Hg}$ during hypotension but only one (patient \#11) had a dangerously high value of $73 \mathrm{~mm} \mathrm{Hg}$. In this case it was difficult to lower the blood pressure with Arfonad ${ }^{\circledR}$. There were no serious sequelae. In these cases continuous measurement of arterial $\mathrm{PCO}_{2}$ with an indwelling $\mathrm{PaCO}_{2}$ electrode would be. helpful. The use of a $\mathrm{CO}_{2}$ monitor for the measurement of the mixed expired $\mathrm{CO}_{2}$ tension would be helpful in the assessment of perfusion of the lungs during hypotension. Unfortunately, neither of these pieces of equipment was available for this series.

Hypotension is of great value in preventing inadvertent rupture of the aneurysm, which may be catastrophic. It is employed to decrease the tension in the wall of the aneurysm. According to the law of Laplace the tension is proportional to the radius times the pressure. ${ }^{8}$ Therefore, a reduction of the blood pressure should reduce the tension in the aneurysm wall. In the event of a rupture during dissection, haemorrhage is usually much less and more easily managed under controlled hypotension. Its use allows complete dissection of the aneurysm with much less fear of rupture and it allows inspection of a doubtful case with relative safety. Thus the surgeon can be bolder with his dissection and ensure that the clip is properly positioned. Repeated application of the clip is possible to be certain that it is in the best possible position.

In the patients under discussion the blood pressure was lowered to a mean arterial pressure of about $40 \mathrm{~mm} \mathrm{Hg}$ during dissection and repair of the aneurysm. It was not considered necessary to use hypothermia to reduce the metabolic rate to protect the brain from low perfusion and associated hypoxia. 


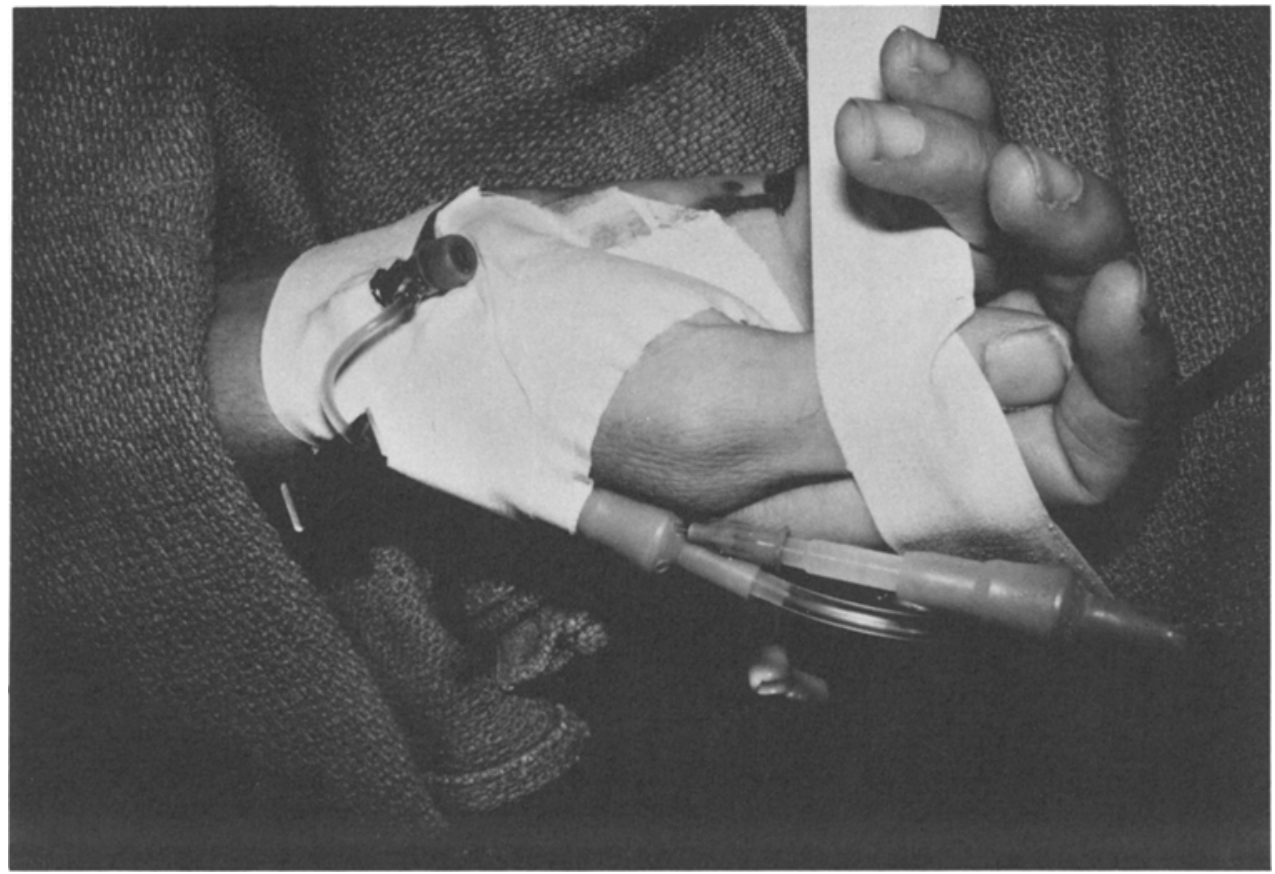

Figure 1. Left-hand with radial artery needle in place.

The use of halothane may have some beneficial effect in protecting the brain from the effects of hypoxia. ${ }^{9}$

Hypotension to a mean arterial pressure of $40 \mathrm{~mm} \mathrm{Hg}$ was achieved either by the use of an infusion of 0.1 per cent of trimethaphan ${ }^{10}$ (Arfonad) or 0.01 per cent of sodium nitroprusside. ${ }^{11}$ Intra-arterial monitoring of blood pressure is essential for the best management of hypotension. The technique that we use is modified from the method of Zorab, ${ }^{12}$ and is accurate only for mean blood pressure. The intra-arterial cannula is usually placed in the radial artery or the dorsalis pedis artery, which are similar in size to the cerebral vessels and will have a similiar mean pressure (Figure 1). Arterial pressure is continuously displayed by a very simple technique using an aneroid manometer. The line is kept patent by continual flushing using a heparinized solution in an intravenous infusion bag pressurized by a "blood pump" (Figure 2). The level of the cerebral cortex was used as a reference point, because we are concerned chiefly with cerebral circulation. If the head is higher than the blood pressure cuff, the resulting reading will be below the mean blood pressure calculated by ausculation of systolic and diastolic pressure from the arm, in a degree proportional to the differences in levels. If the cortex is 13 centimeters above the level of the cuff, the pressure difference between the cortex and the cuff for 13 centimeters of water is $10 \mathrm{~mm} \mathrm{Hg}$. Table IV illustrates the relationship between the systolic and diastolic pressures as measured by the cuff and the intra-arterial mean blood pressure.

It has been stated that a reduction in cerebral blood flows does not occur until 


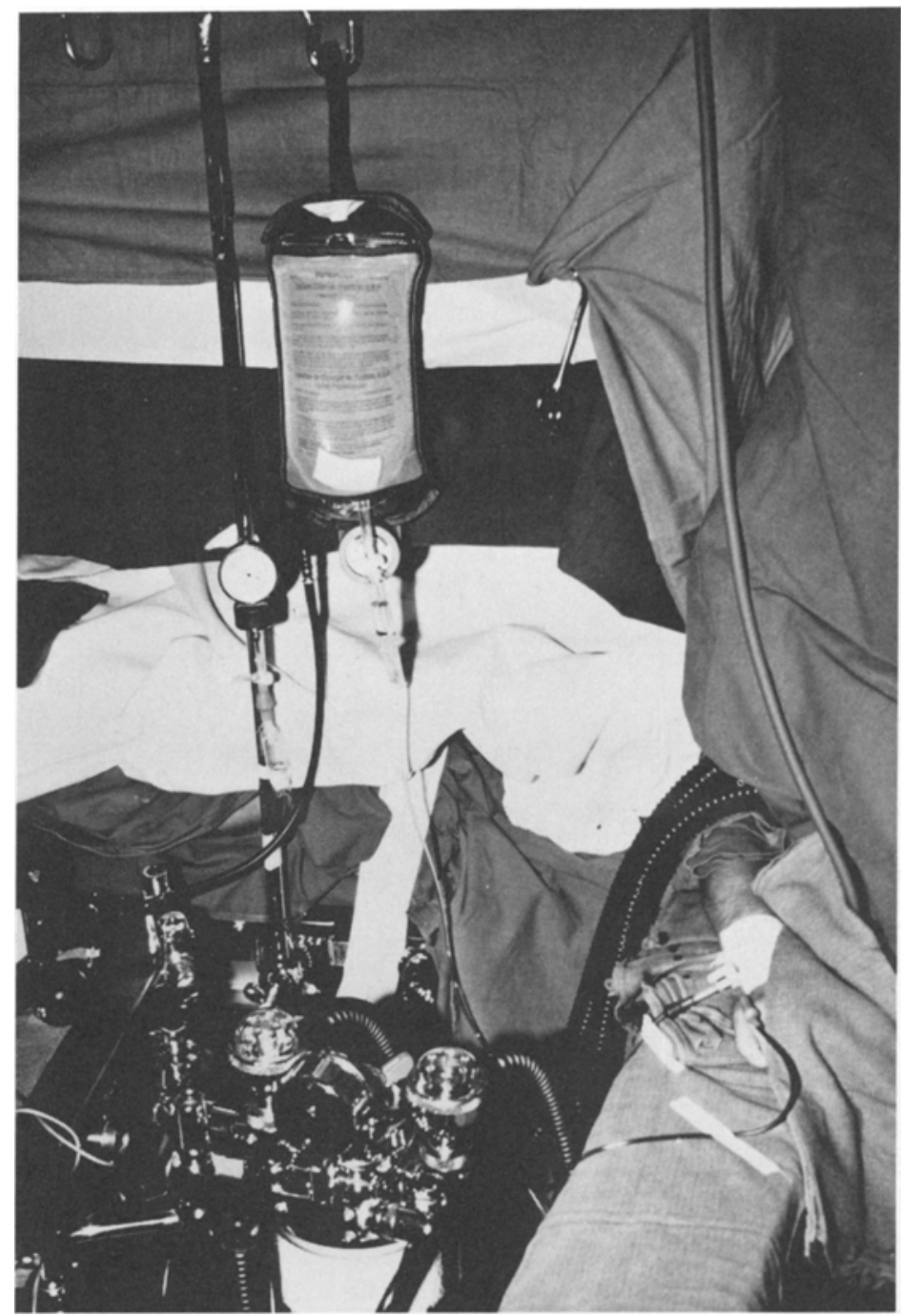

Figure 2. Arterial pressure monitor with aneroid manometer, heparinized flush solution, and fluid level at level of cerebral cortex.

the mean blood pressure falls below $50 \mathrm{~mm} \mathrm{Hg.}{ }^{13}$ In our cases, the blood pressure is lowered below this without major problems although we were not able to measure blood flow. However, the perfusion of the vital centres gives a clinical indication of blood flow. Shallow or irregular breathing is usually seen when the perfusion of the respiratory centre becomes inadequate. This change from the normal respiratory pattern is regarded as an indication to raise the blood pressure by stopping the Arfonad infusion and/or increasing blood volume.

In patients over approximately the past eight years, no serious complications have occurred due to the arterial cannula in the radial artery. Two complications occurred when the cannula was placed in the brachial artery. Recently we have 
TABLE IV

\begin{tabular}{|c|c|c|}
\hline & Normotensive & Hypotensive \\
\hline $\begin{array}{l}\text { Systolic blood pressure } \\
\text { Diastolic blood pressure }\end{array}$ & $\begin{array}{r}120 \\
75\end{array}$ & $\begin{array}{l}55 \\
35\end{array}$ \\
\hline Pulse pressure & 45 & 20 \\
\hline $\begin{array}{l}\text { Calculation } \\
\text { Diastolic blood pressure }\end{array}$ & $45 \times 1 / 3=15$ & $20 \times \frac{1 / 3}{35}=7$ \\
\hline Mean blood pressure & 90 & 42 \\
\hline
\end{tabular}

TABLE V

Results of Cerebral Aneurysm Surgery, Victoria Hospital, 1962-71, with Anaesthetic Technique AS DESCRIBED

\begin{tabular}{lc}
\hline & No. \\
\hline Patients & 326 \\
Grade I patients & 163 \\
Results of surgery on Grade I patients & \\
Excellent to good & 143 \\
Poor results & 11 \\
Deaths & 9 \\
Per cent: excellent to good & $87.7 \%$ \\
\hline
\end{tabular}

used the dorsalis pedis artery for intra-arterial monitoring and no complications have been seen to date. In one patient both the radial and the dorsalis pedis arteries were cannulated and the mean blood pressure was found to be identical in the two vessels.

\section{Results}

Important degrees of hypotension have been used during craniotomy for aneurysms in 326 patients. During the period from mid-1962 to December 31, 1971, 163 patients were operated on who were classified as Grade I. ${ }^{14}$ These patients can be used as controls because, although they had proven subarachnoid haemorrhage from an intracranial aneurysm, they had no neurological deficit. Therefore, deficits associated with the anaesthesia and surgery could not be confused with deficits already present prior to surgery. These patients had aneurysms in all locations and included a large series of 140 basilar aneurysms (Table V).

Of these 163 Grade I patients, 143 had an excellent to good result. This included some patients with a slight deficit that was not disabling. Eleven patients had a poor result and nine patients died. A careful study including postoperative cerebral angiography showed that the induced hypotension was not a factor in causation of the morbidity or mortality. The only known serious sequelae of this degree of hypotension occurred in a 54-year-old hypotensive Grade III patient. 


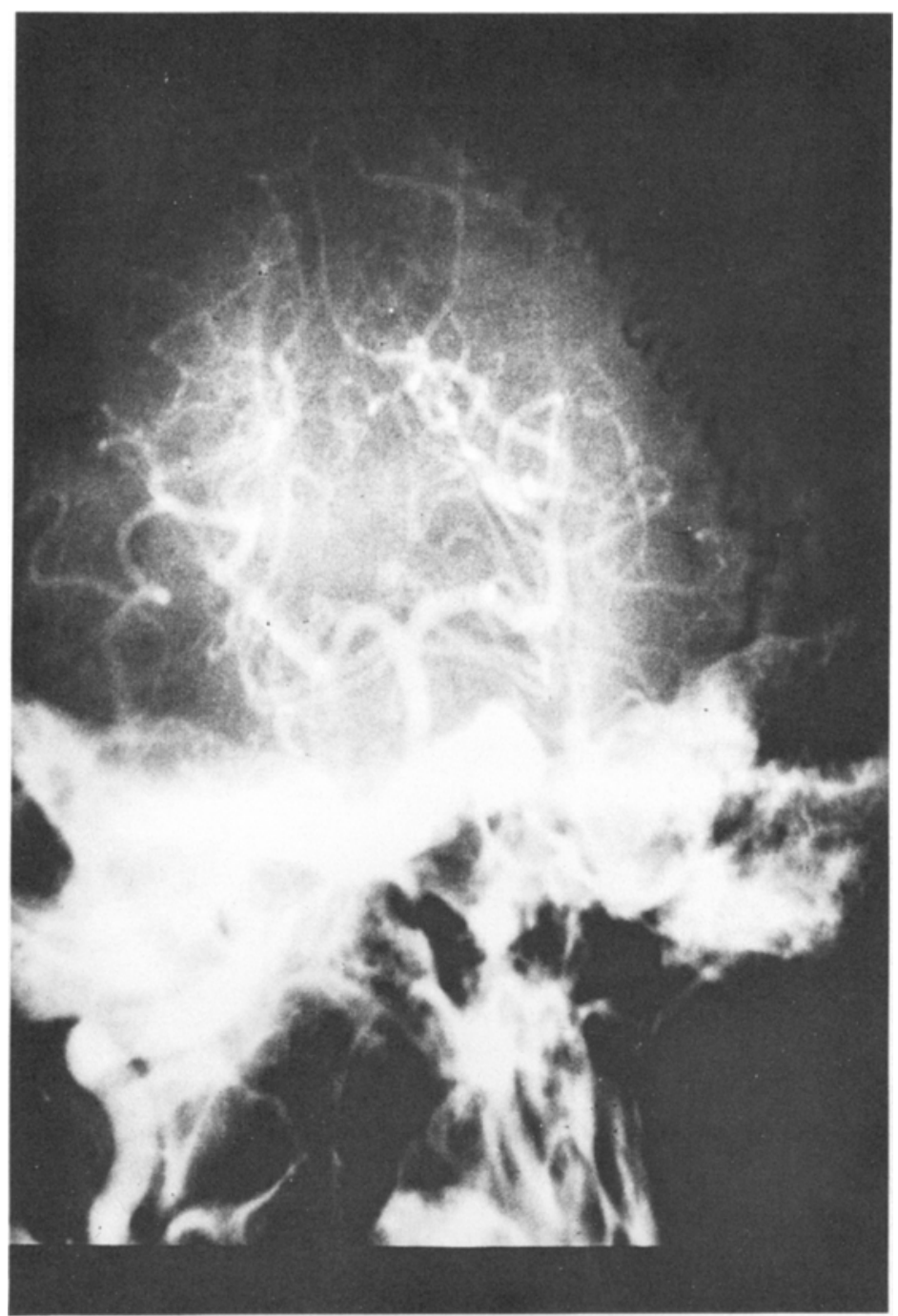

Figure 3. Basilar artery aneurysm on angiogram in patient R.K.

She died suddenly as the aneurysm was to be clipped, although her blood pressure had been at $40 \mathrm{~mm} \mathrm{Hg}$ for only 20 minutes.

It should be noted that the incidence of postoperative arterial spasm has remained about the same over the past 10 years. Generally the patients had better results in spite of this. Therefore, the initial reasoning to avoid hypothermia and controlled ventilation to decrease postoperative arterial spasm may not have been valid. However, the other values inherent in the anaesthetic methods used since 1962 were appreciated since then, especially in the 140 basilar artery aneurysms that were operated upon. 


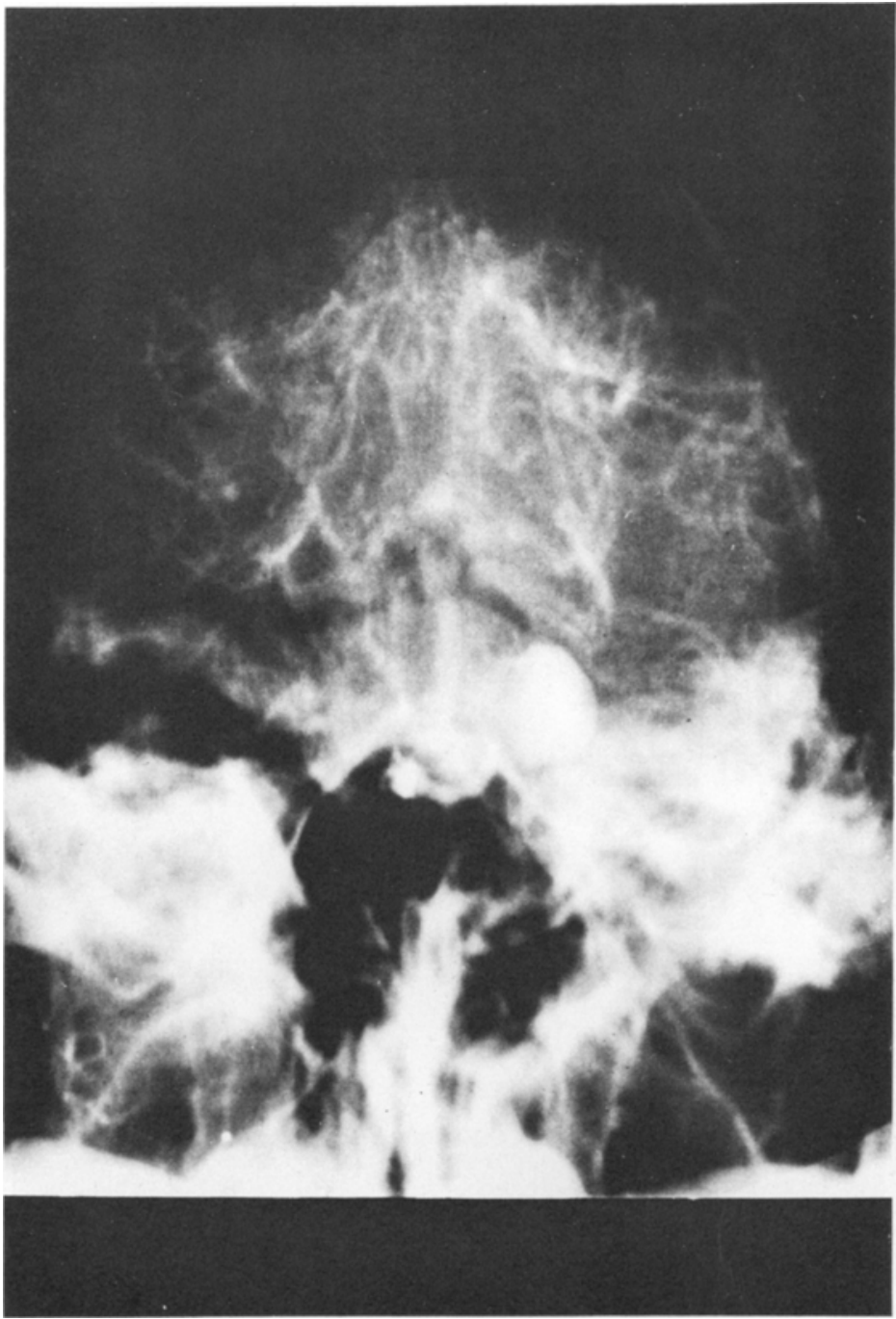

Figure 4. Post-operative angiogram showing curved Heifitz clip that does not occlude neck of aneurysm in patient R.K.

\section{CASE Report}

A young man, R.K., aged 21, had a single subarachnoid haemorrhage from a large basilar aneurysm 31/2 months prior to operation on December 8, 1971. He was unconscious for two hours at that time but at the time of operation had no neurological deficit. His preoperative vertebral arteriogram showed the size and location of the aneurysm (Figure 3).

The patient was anaesthetized in the usual fashion with Innovar ${ }^{\circledR}$, thiopentone and succinylcholine preceded by a small dose of d-tubocurarine. The trachea was intubated. He was allowed to breathe nitrous oxide, oxygen and halothane spontaneously. During dissection and clipping of the aneurysm hypotension to a 


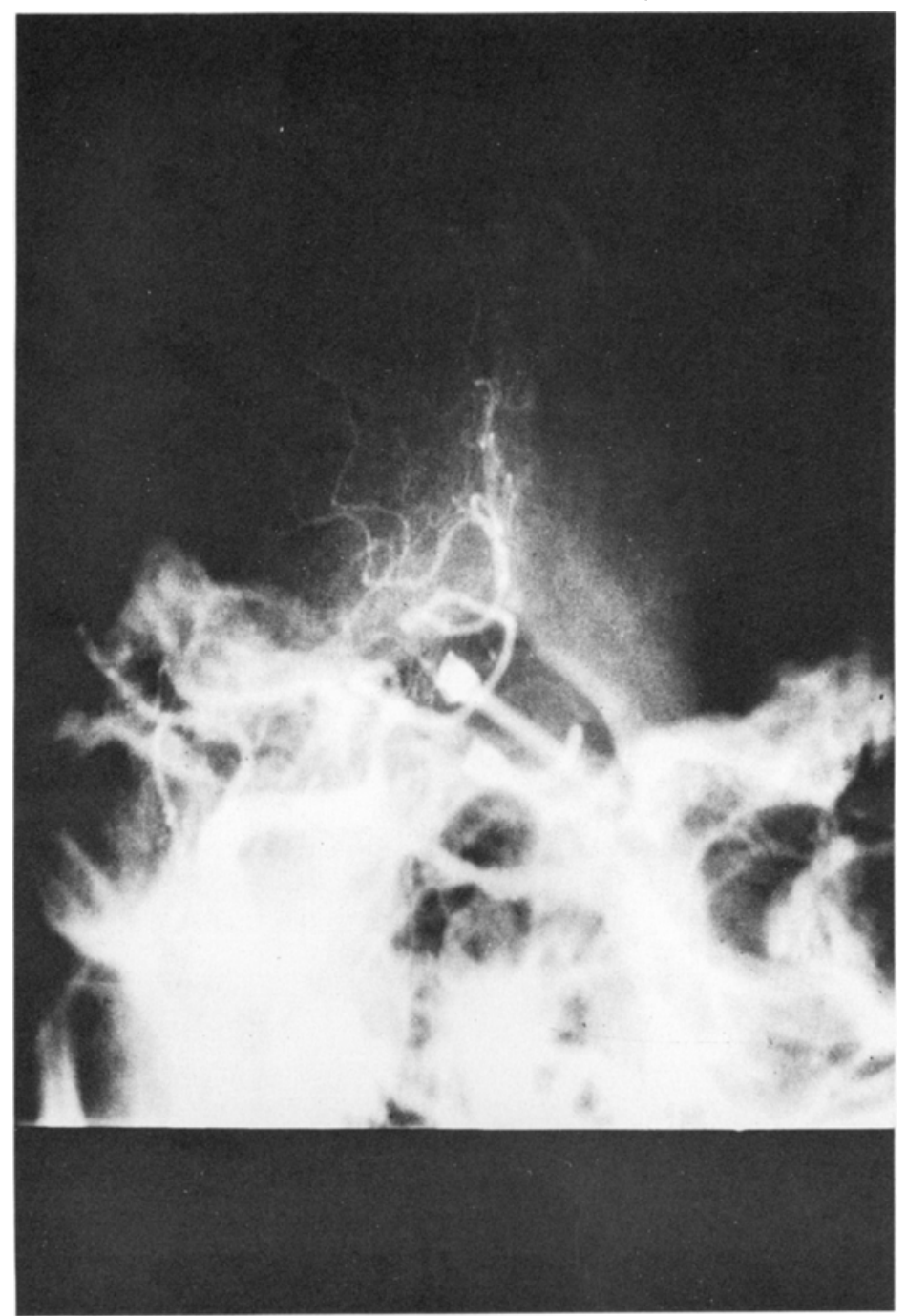

Figure 5. Post-operative angiogram showing neck of aneurysm occluded by straight Heifitz clip applied during second operative procedure.

mean blood pressure of $42 \mathrm{~mm} \mathrm{Hg}$ was maintained for about 60 minutes with intermittent addition of trimethaphan 0.1 per cent solution. The aneurysm was supposedly clipped with difficulty and the patient made an uneventful recovery. However the surgeon was not convinced that the clip was placed correctly so that a postoperative vertebral arteriogram was done almost immediately following operation. This showed that the curved Heifetz clip was not across the neck of the aneurysm (Figure 4).

When the patient was fully awake and had been assessed from the neurological standpoint he was taken back to the operating room for re-opening of the craniotomy. Anaesthesia was similar to that for the first operation and controlled hypotension to $43 \mathrm{~mm} \mathrm{Hg}$ mean pressure for 25 minutes was induced with 
TABLE VI

Blood Gases of Patient R.K. During Two Operations with InDUCED HYPOTENSION ON THE SAME DAY

\begin{tabular}{lccccc}
\hline & $\mathrm{PO}_{2}$ & $\mathrm{pH}$ & $\mathrm{PCO}_{2}$ & $\mathrm{HCO}_{2}$ & $\mathrm{BE}$ \\
$\begin{array}{l}\text { Procedure \#1 } \\
\begin{array}{l}\text { Spontaneous respiration } \\
\text { B.P. 100 mmHg }\end{array}\end{array}$ & 150 & 7.30 & 50 & 22 & -3 \\
$\begin{array}{l}\text { Spontaneous respiration } \\
\text { B.P. 42 mmHg }\end{array}$ & & & & & \\
$\begin{array}{l}(45 \text { minutes) } \\
\text { Procedure \#2 }\end{array}$ & 258 & 7.28 & 48 & 21 & -4 \\
$\begin{array}{l}\text { Spontaneous respirations } \\
\text { B.P. 43 mm }\end{array}$ & 95 & 7.34 & 39 & 21 & -4 \\
\hline
\end{tabular}

trimethaphan. A straight Heifetz clip was positioned across 'he neck of the aneurysm and this was confirmed by post-operative angiogram (Figure 5). By 2330 hours of the same day the patient was awake and oriented and moved his limbs well. He was discharged to his home in Missouri nine days later with only a right 6 th nerve palsy. This patient illustrates a case where both spontaneous ventilation and controlled hypotension without hypothermia were used twice within 16 hours without serious problem. His blood gases during these two operations are shown in Table VI.

\section{Conclusion}

In the surgical treatment of cerebral aneurysms spontaneous respiration is advantageous, especially during hypotension, if the blood gases can be maintained near normal. Hypocarbia is prevented, to avoid its possibly harmful effects on cerebral blood flow and its contribution to postoperative arterial spasm. The pattern of respiration can be utilized as a useful monitor of the perfusion of vital centres.

Hypothermia with its attendent risks may be abandoned, as it has been found unnecessary even when significant levels of hypotension are used. This reduces the anaesthesia time considerably and obviates the harmful cardiac and respiratory effects of hypothermia. The beneficial effect of hypothermia in reducing brain size for better surgical conditions can be achieved more easily and safely by the use of an indwelling lumbar CSF drain with or without Mannitol.

\section{RÉSUMÉ}

Au cours du traitement chirurgical des anévrysmes cérébraux, il y a avantage de maintenir la respiration spontanée, plus spécialement durant l'hypotension si les gaz sanguins peuvent être maintenus voisins de la normale. On prévient ainsi I'hypocarbie pour éviter ses effets éventuels nuisibles sur la circulation sanguine cérébrale et sa contribution au spasme artériel post-opératoire. Le type de respiration peut servir de moniteur utile pour renseigner sur la perfusion des centres vitaux. 
L'hypothermie avec ses risques inhérents peut être laissée de côté, car elle s'est avérée non nécessaire même lorsque des niveaux importants d'hypotension sont utilisés. La durée de l'anesthésie est considérablement réduite et les effets cardiaques et respiratoires nuisibles de l'hypothermie sont évités. L'effet bénéfique de l'hypothermie en réduisant le volume du cerveau pour améliorer le travail chirurgical se réalise plus facilement et avec plus de sécurité par l'usage d'un cathéter pour drainer le liquide céphalo-rachidien avec ou sans usage de Mannitol.

\section{REFERENCES}

1. Altcock, J.M. \& Drake, C.G. Ruptured intracranial aneurysms - the role of arterial spasm. J. Neurosurg. 25: 21 (1965).

2. DRAKE, C.G. The surgical treatment of vertebral-basiliar aneurysms. Clinical Neurosurgery 114-169, The Williams and Wilkins Co. Baltimore (1969).

3. Michenfelder, J.D., Gronert, G.A., \& Rehoer, V. Neuroanesthesia - a review article. Anesthesiol. 30: 65 (1969).

4. JENkins, L.C. General anaesthesia and the central nervous system. Baltimore. The Williams and Wilkins Co. Chap. 8 (1969).

5. Aitken, R.R. \& Drake, C.G. Experience with profound hypotension in intracranial aneurysms - Paper presented at the Harvey Cushing Society Meeting, Washington, D.C. (1971).

6. Bendixen, H.H. \& Laver, M.B. Hypoxia in anesthesia: a review. Clin. Pharmacol, and Therap. 6: 510 (1965).

7. Askrog, V.F., Pender, J.W., \& Eckenhoff, J.E. Changes in physiological dead space during deliberate hypotension. Anesthesiol. 25: 744 (1964).

8. Burton, A.C. Physiology and biophysics of the circulation. Chap. 7. Year Book Medical Publishers Inc. Chicago (1968).

9. THEYe, R.A. \& MichenfELder, J.D. The effect of halothane on canine cerebral metabolism. Anesthesiol. 29: 1113 (1968).

10. Lafson, A.G. Deliberate hypotension. Anesthesiol. 25: 682 (1964).

11. Seigel, P., Moraca, P.P., \& Green, J.R. Sodium nitroprusside in the surgical treatment of cerebral aneurysms and arteriovenous malformations. Brit. J. Anaesth. 43: 790 (1971).

12. Zorab, J.S.M. Continuous display of the arterial pressure. Anaesthesia 24: 431 (1969).

13. Shenkin, H.A. \& Bouzarth, W.F. Clinical methods of reducing intracranial pressure role of cerebral circulation. N.E.J.M. 282: 1465 (1970).

14. Botterell, E.H., Lovgheed, W.M., Scott, J.W., \& VANdewater, S.L. Hypothermia and interruption of carotid or carotid and vertebral circulation in the surgical management of intracranial aneurysms. J. Neurosurg. 13: 1 (1956). 